\title{
Power Struggles and Disciplined Designers - A Nexus Analytic Inquiry on Cross-Disciplinary Research and Design
}

\author{
Netta Iivari \\ INTERACT Research Unit, University of Oulu, \\ Oulu, Finland \\ netta.iivari@oulu.fi
}

\begin{abstract}
Design is at the heart of Human Computer Interaction research and practice. In the research community, there has emerged an increasing interest in understanding and conceptualizing our research practice, particularly such entailing design. However, reflective discussion around the associated challenges and practicalities is yet limited. Moreover, so far there is limited discussion on the crossdisciplinary nature of our research and design practices: although cross-disciplinarity has been brought up as an ideal and a necessity, its practicalities and complexities remain yet poorly explored. This study examines a crossdisciplinary research project with a number of researcherdesigners representing different disciplines acting as 'designers', while having a divergent understanding of it and of who has authority to do it. The study relies on nexus analysis as a sensitizing device and shows how various discourses, epistemologies and histories shape cross-disciplinary research and design. Critical reflection around our research practice entailing design is called for.
\end{abstract}

\section{CCS CONCEPTS}

- CCS $\rightarrow$ Human-centered computing $\rightarrow$ Interaction design $\rightarrow$ Empirical studies in interaction design.

\section{KEYWORDS}

Cross-disciplinary, Multi-disciplinary; Inter-disciplinary; Transdisciplinary; Nexus analysis; Design research; Research into design; Research through design

Permission to make digital or hard copies of all or part of this work for personal or classroom use is granted without fee provided that copies are not made or distributed for profit or commercial advantage and that copies bear this notice and the full citation on the first page. Copyrights for components of this work owned by others than the author(s) must be honored. Abstracting with credit is permitted. To copy otherwise, or republish, to post on servers or to redistribute to lists, requires prior specific permission and/or a fee. Request permissions from Permissions@acm.org CHI 2019, May 4-9, 2019, Glasgow, Scotland, UK.

(c) 2019 Copyright is held by the owner/author(s). Publication rights licensed to ACM. ACM ISBN xxx-x-xxxx-xxxx- $\mathrm{x} / \mathrm{xx} / \mathrm{xx}$.

DOI https://doi.org/xx.xxxx/ $\mathrm{xxxxxxx.xxxxxxx}$
ACM Reference format:

Iivari, Netta. 2019. Power Struggles and Disciplined Designers - A Nexus Analytic Inquiry on Cross-Disciplinary Research and Design. In 2019 CHI Conference on Human Factors in Computing Systems Proceedings (CHI 2019), May 4-9, 2019, Glasgow, Scotland, UK. ACM, New York, NY, USA. Paper 396, 14 pages. https://doi.org/xx.xxxx/Xxxxxxx.Xxxxxxx

\section{INTRODUCTION}

Design is at the heart of Human Computer Interaction (HCI) research and practice. Design, in HCI as well as elsewhere, powerfully shapes our lives. Digital technologies have become thoroughly embedded into all our life spheres and design decisions around digital technology are thus highly influential in our everyday life. Hence, HCI research and practice has the potential of enriching our life but also of making it miserable.

In $\mathrm{HCI}$, there has emerged increasing interest in understanding and conceptualizing our research practice (see e.g. [1, 2, 3, 4, 5]), particularly such that entails creation of novel artefacts. Inspiration for this type of research is derived particularly from Design Research tradition where methods and processes from design practice are seen as a legitimate method of inquiry, the inquiry "revolving around the making of a product, service, environment, or system" (e.g. [3: 310, 6]), with an aim of producing a knowledge contribution if not even a theory, not only an artifact $[1,2,7]$. This discussion is often linked to Frayling's seminal article [8] that identifies research into design, research through design and research for design in Design Research. Research through design in particular has gained notable interest in the HCI community $[1,2,3,7,9]$ and the interest seems only to be raising: for example in the past couple of $\mathrm{CHI}$ conferences, a considerable number of research through design papers has been published, compared to only a few prior that. However, the studies do not necessarily detail how their work represents research through design. Moreover, there 
seems to be quite a lot of variety of what is included under this umbrella term. Additionally, alternative terms have been proposed to discuss HCI research practice including design. Overall, there seems to be space to reflect on our Design Research inspired research practices.

Then again, significant is to acknowledge that HCI is definitely not the only disciplines claiming authority to design. A variety of disciplines seem to postulate design as a legitimate area of expertise, the designers representing these disciplines being equipped with particular method repertoires as well as ontological, epistemological and methodological assumptions. The cross-disciplinary nature of research and design has been acknowledged by HCI - in a sense. HCI discourse strongly argues for crossdisciplinary research and design $[10,11,12,13,14,15,16$, 17, 18, 19]; cross-disciplinarity in Design Research as well as in HCI is seen both as an ideal and a necessity [10, 11, $12,15,19]$. However, there is yet a limited understanding of the practicalities and challenges around crossdisciplinary Design Research in HCI - particularly from the perspective of multiple design disciplines involved. This study will show that reflective discussion needs to be aroused to better prepare HCI researchers for crossdisciplinary Design Research as well as to enrich our yet vague empirical understanding of our research practice intermingled with design.

This paper represents research into design [8] with implications for Design Research, particularly for research through design. A cross-disciplinary research project is examined through a nexus analytic lens. In the project, a number of researchers representing different disciplines engaged in design, each with their own research questions and research motivations, driven by their disciplinary backgrounds. Nexus analysis guides researchers to study particular people, practices, artifacts, and discourses in situ, in real time and place, but also to acknowledge and appreciate more distant discourses, historical backgrounds and trajectories as well as a variety of participants looming in the background, all shaping the in situ action $[20,21,22]$. Nexus analysis is suitable for studying complex topics in depth [20,21,22] - it enables in-depth examinations, taking into account underlying factors and dynamics. This study aims to show the value of nexus analysis in conceptualizing and understanding crossdisciplinary Design Research - taking place among a variety of designers. So far, there is a lack of in-depth empirical inquiries on our cross-disciplinary research practice. The study shows that with the nexus analytic concepts of discourses in place, historical body and interaction order one can reveal fascinating aspects shaping research, design, and researcher-designers speaking through them.

The paper is structured as follows. The next section introduces related research addressing our research practice, the cross-disciplinary nature of research and design, and the nexus analytic theoretical lens. The third section presents the case project as well as the methods involved in its examination. The fourth section outlines the empirical insights and interprets them with the nexus analytic lens. The fifth section concludes the paper by discussing research and design implications, limitations, and paths for future work.

\section{RELATED WORKS}

\subsection{Design Research and $\mathrm{HCI}$}

In $\mathrm{HCI}$, there is increasing interest to understand and conceptualize our research practice (see e.g. [1, 2, 3, 4, 5, 18]). Even if research though design in particular has received a lot of attention in HCI research $[1,2,3,9]$, it needs to be acknowledged that there are multiple traditions and views according to which combine research with design in Design Research. Cross [23] offers a famous discussion on the variety involved: he discusses scientific design, design science, the science of design, and design as a discipline, with divergent ontological, epistemological and methodological assumptions. Design science discussed by Cross [23] aims at scientizing design - at formulating a coherent, rationalized scientific method for design: it refers to "an explicitly organized, rational, and wholly systematic approach to design; not just the utilization of scientific knowledge of artifacts, but design in some sense as a scientific activity itself." [23: 53] Design science has received huge popularity recently in Information Systems (IS) research community (see e.g. Hevner [24], inspired by [25]).

Cross himself [23], then again, argues for viewing design as a discipline in itself: not trying to fit it into the scientific method, but instead aiming to understand it as a rigorous culture of its own. Research through design can be located within this strand to Design Research. However, Koskinen and colleagues as well as others have criticized research through design as a fuzzy term (e.g. [3, $6,7]$ ), and the fuzziness still seems to prevail, at least in the $\mathrm{CHI}$ articles reporting on its use. Alternative labels have also been introduced to research through design, constructive design research as an example [6]. Stappers and Giaccardi [9] identify a number of alternative labels 
that they see as jargon to refer to designerly ways of doing research.

Even if somewhat different labels of this type of $\mathrm{HCI}$ research are used, there seem to be a shared, even though somewhat vague, understanding of what this type of research entails. In general, there is an acknowledgement in HCI that this type of research aims at changing the world through design [2] and it should be "appreciated for its proliferation of new realities" [1] and "multiple ways of being in the world" [26: 194]. In addition to an artefact, a knowledge contribution, potentially in the form of a theory, is needed $[1,2]$. However, challenging is that we are dealing with a generative discipline that changes the context in which it operates; hence, consensus and single standardized conduct should not be expected and also theories need to be seen as generative and suggestive [1]. Design examples are also to be valued as significant outcomes of research: they capture the multitude of design decisions and design knowledge of their creators there are implicit theories embodied in them [1]. Around these design examples, annotated portfolios are also recommended as capturing reflection around them discussing the joining and differentiating aspects of them [1].

The literature clearly distinguishes this type of research from design science and the scientific method. In the discussion, a creative view of design [27] is clearly emphasized: invention, imagination, expertise, judgement, meanings making, reflection, and improvisation of professional designers is underscored [1, 2, 6, 23, 26, 27, 28]. Additionally, in some of the texts, a participatory view of design [27] is clearly articulated: various kinds of communities and stakeholders are seen as necessary participants and contributors to design [6, 27, 28, 29]. This type of Design Research tends to be connected with the Participatory Design tradition, in line with which a conflict-laden view of the design may also picture strong: conflicting interests and agendas within any design process are then highlighted, the question of whose interests are being served is raised, ethical responsibilities of the designer are accentuated, and questioning of the status quo and/or empowerment of the oppressed are prioritized (e.g. [28, 29, 30, 31, 32]).

As the discussion shows, there is considerable variety in the Design Research in HCI, the implications of which have not yet been fully explored in HCI. Additionally, so far there is a limited understanding of the practicalities and brute reality of Design Research in HCI. This paper wishes to open a space for reflection around our research practice that entails design.

\subsection{Cross-Disciplinary Research and Design}

Studies discussed in this section address work involving several disciplines, regardless of whether the actual label used in each study is cross-, multi-, inter-, or transdisciplinary or whether a study merely mentions the involvement of several disciplines. The label crossdisciplinary is used as an umbrella term in this paper to cover this variety. Multi-, inter-, and transdisciplinary refer to a continuum that includes increasing amounts of interaction and cross-fertilization among disciplines. Multidisciplinary work involves several disciplines working independently (in parallel or sequentially) in an additive, not integrative manner; interdisciplinary work entails reciprocal actions among disciplines, solving of shared problems, and integration of knowledge; and transdisciplinary work involves work across or beyond disciplines, transcending disciplinary boundaries and transforming the disciplines [33].

HCI research strongly argues for cross-disciplinary research and design $[10,11,12,13,15,14,15,16,17]$ : researchers and designers alike need to work in teams that include people representing different disciplines and professions, relying on, taking advantage of and combining each other's specific while complementary types of expertise (e.g. [10, 11, 14, 15, 16, 17]). The field of $\mathrm{HCI}$ itself is influenced and transformed by a number of disciplines thorough its lifespan $[10,11,15]$. Transdisciplinary design has even been suggested as the fourth design paradigm of interaction design education, scholarship and practice [12].

There already are some empirical studies addressing cross-disciplinary research or design. Related to divergent disciplines or areas of expertise involved in design, the most prominent distinction is between the areas of expertise of users and designers, whose collaboration has been addressed extensively in the literature, particularly within the Participatory Design tradition [29, 34, 35]. Another strand of research has addressed the role of HCI specialists as representing users in design and the challenges involved in their work [36, 37, 38, 39]. In recent years it has also been revealed that there might be even more diversity in design: multiple communities, organizations, areas of expertise, and disciplines may be involved and there may be many challenges (e.g. [40, 41, $42,43,44])$ : communicating, collaborating, and arriving at shared understandings may all be very difficult [40, 41, 42, 
43, 44]. There is a possibility of mismatches in design goals, language, assumptions, practices and understandings $[10,14,16,46,47]$. Different design disciplines may also be addressing the same problem without clear guidelines on how to combine the contribution [14]. Studies also report challenges in crossdisciplinary research. The systems related to accountability, legitimation, evaluation and reward are not necessarily compatible and there may be variety in the ontological, epistemological and methodological assumptions held by researchers representing different disciplines [15, 17, 45]. A lot of discussion, negotiation and learning may be needed by researchers $[10,15,46]$. Due to the challenges, HCI research has proposed suitable tools and practices to help communication, collaboration and reaching a common ground $[10,15,16,47]$.

However, despite these studies, there still is a lack of empirical research examining in-depth the complexities involved with cross-disciplinary research and design in practice. If cross-disciplinarity and its challenges are addressed, this tends to be done from the perspective of user groups or communities involved or from the perspective of collaboration with other disciplines than design. The literature seems to position the Design Researcher rather as a conflict resolver and sympathetic facilitator than as active agent in the struggles with her vested interests, agendas and disciplinary baggage. Overall, it seems that HCI research so far has shied away from critically scrutinizing and reflecting on our own Design Research practice and on cross-disciplinarity within. This study next proposes a novel lens for doing so.

\subsection{Theoretical Lens}

Nexus analysis provides a cross-disciplinary research strategy and theoretical lens that has derived inspiration from a variety of fields such as sociolinguistics, conversation analysis, anthropological linguistics, ethnography of communication, critical discourse analysis, practice theories, activity theory, social semiotics, multimodal discourse analysis, new literacy studies and cultural geography [22]. Due to the origins, linguistics and discourse analysis play a prominent role in this research strategy, while nexus analysis specifically emphasizes that the interest should be both in discursive and non-discursive practices through which our social reality is constituted [22]. Nexus analysis sees social action as the central unit of analysis [20] that is seen to be constituted by three aspects: historical bodies of the participants, interaction order among the participants and discourses in place circulating around [22].
The concept of historical body was coined by philosopher Nishida and the concept directs our attention to how people's personal experiences and accumulated life histories, i.e. their historical body, shape their behavior [21]. Bourdieu's [48] concept of habitus refers to a similar phenomenon: it is formed through an evolving social process and it underlies and guides people's behavior and thinking. During people's lifespan, various kinds of capital are acquired - economical, cultural, and social. Habitus can be seen as embodying such capital. However, in nexus analysis the concept of historical body is preferred instead of habitus, as it more explicitly includes the bodily aspects. Overall, the concept of historical body is to shed light on the variety of experiences and expertise that is shaping and underlying our action [21, 22].

The concept of interaction order was coined by Goffman [49] and the concept addresses social interaction among people and how it is constituted. Here, important are the interactional, socially situational aspects, including participants' engrossment, involvement and attention as well as the broader conventions, norms and rules that are involved in maintaining social order. Nexus analysis acknowledges that people behave differently depending on with whom they are [21]. Therefore, it is important to acknowledge the variety of participants in any social action - those actually present and the more distant ones [21].

As mentioned, discourses are another significant aspect involved in any social action. Nexus analysis acknowledges that there is a complex interplay between discourse and action. Related to any social action one needs to ask: what is the role of discourse in that action, who produces it, why and with what kind of motives [20, 22]? Nexus analysis acknowledges both micro and macro levels: face-to-face encounters between participants in social action in situ as well as broader sets of concerns circulating around in society. One of the main tasks of nexus analysis is to "explicate and understand how the broad discourses of our social life are engaged (or not) in the moment-by-moment social actions of social actors in real time activity" [20: 139]. This leads the analyst to examine specific moments of interaction in real time and place but also to engage in a broader socio-political-cultural inquiry of societal issues, concerns and power interests [21]. The concept of discourses in place also forefronts that all social action takes place in real time and place by human actors and their bodies [21].

Nexus analysis has been utilized to study a variety of topics within a diversity of disciplines, while it has also 
been utilized to understand technology-mediated social action (e.g. [21, 50, 51, 52]). Nexus analytic framework is seen as valuable as it enables in-depth inquiries taking into account underlying issues and dynamics. It guides to study both discourse and action and always to acknowledge also materiality and social and historical aspects. Their intertwining is also underscored; they are all present in any social action and entangled in complex ways. Historicity leads also to studying trajectories of how events, people, ideas, objects and knowledge evolve over time $[21,50]$.

\section{RESEARCH SETTING AND METHODS}

This study reports on a multinational and crossdisciplinary research project developing a learning application. The project partners come from several countries and organizations ranging from research institutions to Information Technology (IT) companies. The research institutions have expertise in IT, HCI and/or educational sciences.

This study reports results from an interpretive case study on the project. In line with interpretive research tradition, in this study it is assumed that "our knowledge of reality, including the domain of human action, is a social construction by human actors. Our theories concerning reality are ways of making sense of the world, and shared meanings are a form of intersubjectivity rather than objectivity" [53: 320]. Hence, an epistemological stance that denies a "naïve realist view of representation", which views meanings as fixed entities that can be discovered by researchers, is adopted. This study underscores the socially constructed nature of research results and research material. Hence, "facts" are seen as socially constructed, even though it is assumed that better and worse interpretations can still be distinguished [54]. The author of the paper acted in the research project as an "involved researcher", instead of an "outside observer" (in line with interpretive tradition and nexus analysis [21, 55]). As such, she had a direct personal stake in the outcomes and interpretations, and she was able to get a direct sense of the field from the inside [55]. She was involved in the project already when funding was applied, and acted as a supervisor of more junior researchers working on the project. Therefore, she acted both as a participant and as an observer in the project. She represents one of the HCI specialists and has a voice in the design discourse.

Interpretive tradition views research as " $a$ situated activity that locates the observer in the world. It consists of a set of interpretive, material practices that make the world visible. These practices transform the world. They turn the world into a series of representations, including field notes, interviews, conversations, photographs, recordings and memos to the self' [56: 3]. The representations that transformed the world emerged in this case during over three years' time period, and they contain some preparatory work before the official start of the project as well as three years of actual project work. The representations consist of documents produced during the timeframe. The documentation was created independently of this research interest for the purposes of the project, but it was collected together to form the research material to be examined. The number of individual files was several thousand during the initial screening. When the design of the tutor feature became a focal point of analysis, the number of individual files was cut down to around 500. This data includes official project plans, formal project deliverables (requirement, design and evaluation documents), different kinds of memos and informal documents (e.g. sketches, drawings) and email discussions among the project partners. As this project was multinational and distributed endeavor, project happenings indeed are very extensively captured in the project documentation.

In the data analysis, nexus analysis [21] was utilized as a sensitizing device. Especially its concepts of historical body, interaction order and discourses in place [21] framed the analysis. Nexus analysis necessitates starting the analysis of real time doings and sayings - looking at what is going on and what is the role of discourses in what is going on [21, 22]. The documentation produced during the project enabled to examine this: they captured traces of events, people, ideas, objects and knowledge [50]. They also enabled looking at historicity: they revealed trajectories [21] - trajectories of how the events, people, ideas, objects and knowledge had evolved over time [50].

In the analysis first a general level chronological outline of the project happenings was made based on browsing through all the texts. To understand this longterm collaborative process, the focus was on whose voices were present, who were heard and what was said. A chronological account was created. At this point, the technique of member checking was utilized: a case study write-up was delivered to the project participants for comments, and corrections were made based on the feedback and some direct citations removed, as requested by a participant. Through this highly data driven analysis, it appeared that the tutor feature was among the hot 
topics in the project: there was a lot of discussion thorough the years, different parties taking part in them and different views being expressed. Also users were actively involved. Hence, at this point it was decided that the tutor feature will be the specific focus of attention. All the individual files addressing it were screened and all relevant snippets of texts were saved into one lengthy document. The most focal documents addressing the tutor feature were also saved for detailed analysis. The documents and text snippets were then inquired by utilizing the nexus analytic concepts: by considering what kind of historical body and interaction order related issues were shaping the social action of design of the tutor feature and what kind of discourses could be identified as circulating around. Writing this story, a necessary part of any qualitative research $[56,57,58]$ finalized this analysis: just like cultural accounts are stories produced by anthropologists [57: 6, 56], the following account of the design of the tutor feature is a story crafted by the analyst, with an aim to generate an enticing storyline to capture the interest of the reader.

\section{DESIGNING A TUTOR FEATURE}

Educational science specialists, HCI specialists, and IT specialists all acted as designers of the tutor feature. Next, the evolving design process is characterized.

\subsection{Educational Science Specialists Ideating, Theorizing and Designing the Tutor}

The educational science specialists were highly influential in the project. They had ideated the project and they adopted authority to define the requirements for the forthcoming learning application. They had experience in developing an earlier, more limited version of the application, and both theoretical and empirical understanding of the domain of the application. Some of them also followed up technological developments in the area, based on which they saw multiple opportunities to augment learning and serve the learners even better.

When the project started, the educational science specialists took an active role in identifying and imposing requirements for the application. They communicated the requirements to the project partners through PowerPoint slideshows, tables and hand-drawn scenarios of use. They identified requirements from various sources: from the requirements, designs and shortcomings of their earlier version of the application, from various educational science theories and from recent advancements in technology. Also personal preferences were important:
"Attached is a UI design as a PowerPoint show [of the earlier version] ... There are the things pretty much crystallized." "Here you find three persons improvising with iPhones. [An educational science specialist] especially liked this ... Multitouch screen is really wonderful for this." They introduced a Mobile Agent early on in their texts that "Encourages into social interaction; Guides the user to proceed into the next decision in the sequenced task; Provides feedback; Encourages into self-assessment."

In their more formal requirements specification, the educational science specialists relied strongly on their theoretical knowledge: they justified the tutor feature, among other features, through a literature review and associated scientific references. Here, they utilized a theory inspired expert voice: "Scaffolding aims to increase the difference between what a learner can do independently and what the same learner can do when tutored (Vygotsky 1978). (...) The subsequent features of efficacious tutoring are needed:..."

The educational science specialists were also placed responsible for specifying the software requirements of the application. This was not achieved without problems, however. The educational science specialists voiced their unfamiliarity with such a task and asked for help. However, as the other partners did not provide such, the educational science specialists had to create the document and in doing so rely on their own requirements documentation and some documents crafted by the HCI specialists as a basis. However, a HCI specialist stepped in and criticized the outcome as confusing design solutions with requirements. As an example, a requirement for the tutor feature was given, related to which it was pointed out that numerous design decisions had already been made. At this point, the educational science specialists pointed out: "The project plan was mostly constructed by non-software focused people, who created the entire research idea. We [the educational science specialists] only had some tiny little background experience on developing the [earlier] application. We were not familiar enough what a project like this could bring in front of our eyes." The HCI specialists agreed with the challenge and modified the requirements document to become satisfactory.

After the requirements specification, the educational science specialists became engaged in very practical design work. They created an educational design document in which they defined, e.g., the tutor feature in detail, including textual descriptions as well as graphical presentation of each screen: "The tutor, a sympathetic teddy bear helps the user (...) The user can ask the help from 
the tutor by touching the teddy bear. The tutor enlarges before speaking and shrinks afterwards" "The tutor speaks and moves ... indicating successful performance of a task". Afterwards, the educational science specialists delivered the outcome for the $\mathrm{HCI}$ specialists to evaluate with users. At this point, a struggle on design authority between the educational science specialists and HCI specialists started to surface more clearly.

\subsection{HCI Specialists Evaluating and Refining the Tutor}

The HCI specialists were expected to ensure "usercenteredness" and "usability" of the application. The HCI specialists started the project mainly by commenting on the work done by the educational science specialists. However, a significant task and research interest of theirs was to invite users into the design process. With users, feedback to the earlier version and to the educational science specialists' designs as well as users' own ideas, designs and preferences were gathered. Various kinds of design and evaluation sessions were organized. Users commented and supplemented parts of the educational science specialists' scenarios, created low-tech prototypes of their own learning application and designed e.g. icons for the application.

Based on their user data and educational science specialists' scenarios, the HCI specialists identified usability requirements for the learning application. Afterwards, they created a usability design for the application that described the user interface and user interaction with the application. They extensively paper prototyped with users to ensure that the design was suitable for users. Later on, they organized comprehensive usability testing with users to evaluate the prototypes the IT specialists had by then created. They also carried out expert usability evaluations relying on well-known $\mathrm{HCI}$ heuristics and guidelines.

As mentioned, there emerged some conflict between the HCI specialists and educational science specialists already during requirements specification, when the $\mathrm{HCI}$ specialists criticized educational science specialists' requirements as too "designy", indicating the educational science specialists lacked knowledge on requirements and design: "[Requirements] produce information on what will be implemented, but you do not need to design the user interface. So, there just needs to be the information, in one form or another, on what needs to be available, we will produce the user interface design." The same discussion emerged when the project partners collaboratively specified the software requirements, for which the educational science specialists were primarily responsible. The HCI specialists took the responsibility to finalize the software requirements specification. During this trajectory, they indicated possessing good knowledge in software engineering, not only in $\mathrm{HCI}$ and design.

There were also controversies around design later on. The HCI specialists started their usability design by evaluating with users the scenarios provided by the educational science specialists, based on which the $\mathrm{HCI}$ specialists created their design. The educational science specialists, however, had continued their work with the scenarios which resulted in the HCI specialists not evaluating and building on the most recent ones. An IT specialist pointed out that the work done by $\mathrm{HCI}$ specialists should be used as a basis of educational science specialists' design to avoid overlapping work: "[HCI specialists] have sketched quite detailed design for [the application]. It is based on your scenarios and has been usability tested (paper prototyping). The student group has made magnificent work! ... (Fust to remind to make sure that you are not doing overlapping work)" However, the division of work related to design was never settled in the project. Both parties, in parallel, produced their own design documents that were scheduled to be finished at the same time.

As a result, the project ended up in having two overlapping and conflicting designs - addressing the learner or the user. The HCI specialists criticized the situation: "We are wondering here together with [a HCI specialist] that why the user interfaces have been made again, and our findings from the project during last spring have been neglected? The project gathered feedback and generated new ideas based on the scenarios produced [by the educational science specialists]. Now it seems that our feedback has been neglected but the work seems to continue from the own scenarios. I would say that we should prefer designs that already have been evaluated with users." The educational science specialists replied that they had not created the user interfaces anew, but the HCI specialists' documents were not satisfactory. Nevertheless, the educational science specialists were willing to make changes according to the HCI specialists' recommendations, e.g. "Traffic light should appear and grow larger by pressing the tutor". However, also disagreements endured. When rejecting the HCI specialists' suggestions, they referred to educational science theories, to their authority to design the content of the learning application as well as to user interface consistency. 
After the design work, the IT specialists started building prototypes based on the designs, including the tutor feature. The HCI specialists again took an active role with their evaluation work. In their expert evaluations the HCI specialists relied on HCI guidelines and heuristics and commented on the tutor, e.g.: "Navigation icons are not consistent - sometimes uses a picture of the previous screen, sometimes uses a close icon, on main screen has a picture of the bear going through a door." "The guidance given by the teddy remains too limited. (...) When there is no user manual in the game, the guidance given by the teddy should be clear and comprehensive." They also pointed out that the tutor may limit efficiency of expert users: "The only means to fasten the use is to press the picture of the teddy, when it comes to give guidance. Then the teddy goes away. Should users be allowed to remove the teddy from use?"

The HCI specialists also brought in users through usability testing. Users seemed to enjoy the company of the tutor and the encouragement and help: "In the beginning the tutor's guidance are absolutely necessary for the ease of use and learnability of the game" "Users could hear his speech and were noted to be listening to him (...) one user immediately responded "cool, thanks"." However, the response was not only positive, but the users pointed out also a number of negative issues. The most serious concern was that the users became annoyed by the interruptions caused by the tutor: "A lot of users found the tutor highly frustrating. Most of this was due to difficulties with disabling the tutor, as described before, but also with the fact that it re-appeared again too often, interrupting their work (...) Users would often be heard to say "shut up!" and "move away!" when the bear re-appeared ... they developed a game of "kill the bear", in which they hit the screen repeatedly as hard and fast as they could, to try and make him go away." Overall, several targets for improvement were identified as regards the design, while the most significant issue was the possibility to disable the tutor.

\subsection{IT specialists Negotiating the Tutor}

Early in the project, the IT specialists mainly commented on the requirements and designs created by the educational science specialists. In addition, they indicated technological possibilities that could be considered in the project. "I have been thinking about this multi touch (or actually multi point) thing ... I tried this out and I think it works pretty well! There is a demo program. Try it out! Is this enough for us?" "About effects of icons. I just made this video of current implemented situation. Elements in stage are moving all the time. When element is dragged on timeline it transforms (slowly and nicely) its original shape and then stop all effects."

For the software requirements specification, the IT specialists did not contribute much, but they agreed that the division of work and the methods used were unsuitable: "Our process is far from ideal (...) The deliverables were originally meant to be written by nonsoftware professionals (...) We (SW persons) have participated in many video conferences and physical meetings where the requirements were discussed. However, it was not exactly clear to us what non-software people really wanted software to do, nor did we have enough time to decipher that. We tried to tell them what is possible and feasible, and what is not, but after all it was planned that non-software people are writing down their thoughts finally. If the requirements elicitation should have been done by software people, the division of work should have been totally opposite."

The IT specialists did not contribute much to the design discussions either, but they commented on the design, emphasizing users' familiarity with existing conventions: "I think it is worth thinking about how intuitive this is for users. Top right is a nice place for 'close' commands but I'm not convinced whether this is the same for 'back'. In web or image browsing back is usually always represented by an arrow pointing to the left at the far left of the screen."

The IT specialists started creating prototypes as soon as the designs were available. Such prototypes were then evaluated by the HCI specialists and users. Based on the feedback, the IT specialists were ready to make improvements. They invited all participants to negotiate the improvements. Particularly, there was an acute need to enable users to 'kill the bear". The IT specialist preferences as well as existing conventions were shaping the solution: "I do not prefer double clicking. It is very easy to happen by mistake (...) The bear starts to shrink after the first click, so it is very easy to miss it when trying to click him second time. Actually, double clicking is not usually used in touch screens."

\subsection{Nexus Analytic Interpretation}

Nexus analysis enables approaching any social action as both discourses and concrete actions as well as recognizing the role material, historical and social aspects always play in social action. Hence, nexus analysis views any social action as residing in the intersection of discourses in place, historical bodies of the participants and interaction orders among them [21]. When 
characterizing design of the tutor feature as social action, essential is, to begin with, to recognize that three distinct groups of designers emerged in the design process: the educational science specialists, the HCI specialists and the IT specialists. Users were not invited as designers into the process; their contribution was mediated by the $\mathrm{HCI}$ specialists. The educational science specialists acted as authoritative designers in this design process; they initially provided the requirements and the designs for the forthcoming application, inspired by their earlier experiences of developing a more limited version of the application, by technological developments and by educational science theories. They also welcomed the HCI specialists and IT specialists to comment on the requirements and designs. The HCI specialists, then again, worked extensively with users and mediated user feedback and ideas to the design process; hence, they represented users in the design process (cf. [36, 38]). The IT specialists, on their part, implemented prototypes following the designs created as well as commented on the designs and proposed technological opportunities to be considered.

Nexus analysis requires the analyst always to examine discourses circulating around [21]. Table 1 outlines two influential design discourses in the design of the tutor feature as well as the positions allowed for the designers, users and the tutor in the discourses.

Table 1. Design discourses shaping the social action.

\begin{tabular}{|c|c|c|c|c|}
\hline Speaker & Discourse & Designer & User & Tutor \\
\hline $\begin{array}{l}\text { Educational } \\
\text { science } \\
\text { specialists }\end{array}$ & $\begin{array}{l}\text { Theory driven pedagogical } \\
\text { design discourse; created and } \\
\text { negotiated the design }\end{array}$ & $\begin{array}{l}\text { Theory } \\
\text { inspired }\end{array}$ & $\begin{array}{l}\text { Support, guidance, } \\
\text { encouragement requiring }\end{array}$ & $\begin{array}{l}\text { A friendly, sympathetic, } \\
\text { encouraing, guiding creature }\end{array}$ \\
\hline $\begin{array}{l}\mathrm{HCI} \\
\text { specialists }\end{array}$ & $\begin{array}{l}\text { User centered, participatory } \\
\text { design discourse; created, } \\
\text { challenged and negotiated the } \\
\text { design }\end{array}$ & $\begin{array}{l}\text { Usability or } \\
\text { user inspired }\end{array}$ & $\begin{array}{l}\text { Support, guidance, and } \\
\text { encouragement requiring vs. } \\
\text { quick and self-confident; } \\
\text { influential participant in design }\end{array}$ & $\begin{array}{l}\text { A consistent, encouraging. } \\
\text { guiding creature vs. a } \\
\text { frustrating, limited, illogical } \\
\text { creature to be killed }\end{array}$ \\
\hline
\end{tabular}

In this project, two influential design discourses could be identified. The educational science specialists and $\mathrm{HCI}$ specialists relied on and reproduced them: the educational science specialists a theory driven pedagogical design discourse and the HCI specialists a user centered, participatory design discourse. The educational science specialists' theory driven pedagogical design discourse was definitely influential in the project. They grasped authority to settle the requirements and designs that both were strongly theory driven. The HCI specialists entered the design process with their user centered, participatory design discourse that mainly derived its legitimacy from user data. In their accounts, they shared the assumption of the educational science specialists in many respects. However, they also pointed out that users may be quicker and more self-confident than assumed and thus might perceive the tutor as frustrating. The HCI specialists also revealed that some users approached it in a hostile manner.

The concept of historical body [21] enables to consider further the influence of participants' backgrounds, histories and experiences as shaping the social action in question (see Figure 1). Quite evident was the influence of the design participants' familiarity and interest in technology. The earlier version of the application created by the educational science specialists was their baggage and given as the basis for the design process. Some IT specialists and educational science specialists were also quite technology savvy; actively following technology developments and letting those and their preferences strongly shape their ideas of the learning application.

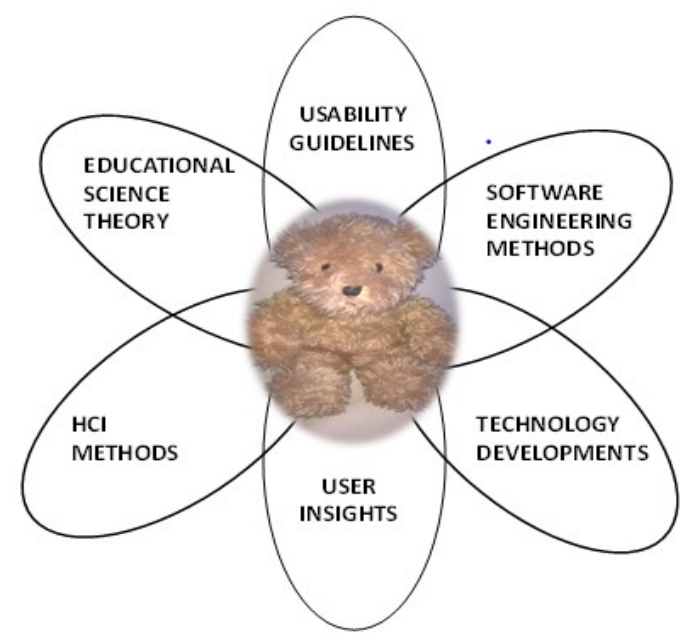

Figure 2. Facets of interaction order and historical body shaping the social action

Moreover, the concept of historical body enables to foreground the influence of different disciplinary systems shaping the design process. The disciplines of HCI and educational science emerged as influential, while also 
software engineering had some legitimacy. The educational science specialists relied in their design work on educational science theories and ideas, starting from no less than Vygotsky. This was assumed to allow them a position within which it is legitimate to articulate what is suitable for the learner in a learning application design. Then again, the HCI specialists were equipped with famous HCI methods and tools. They relied on HCI guidelines and heuristics in evaluating the design and even more importantly they relied on user-centered and participatory design that necessitate collaboration with users. They also compellingly argued for certain changes in the design based on user feedback. In this case, one can say that HCI methods were strongly making some of the designers - the HCI specialists. However, totally divergent disciplinary background was making the educational science specialists as designers. Software engineering played a minor role in design. The IT specialists merely implemented the designs without assuming authority to design the tutor feature. However, the HCI specialists' and IT specialists' shared disciplinary background in software engineering allowed them authority in the requirements activity vis-a-vis the educational science specialists.

The concept of interaction order [21] highlights that the participants' situational interactions and relationships as well as more general conventions, norms and rules shape the social action in question. Various interaction orders were established and emerged in this project. The educational science specialists grasped an authoritative position in the project to begin with: they initiated and ideated the entire project and proposed a lot of educational science inspired ideas on the application design. The HCI specialists and IT specialists joined in later on and seemingly agreed upon this power structure. However, it became challenged during the requirements and design, where the HCI specialists grasped more authority to settle the design.

Then again, during the project planning phase, the participants had collaboratively established many interaction order related issues such as the schedule and division of work. They created some struggles and received a lot of criticism later on, when the educational science specialists recognized their lack of expertise in the requirements activity and when different groups of designers ended up in doing overlapping design work.

Not only software engineering but also HCI methods and models heavily structured the project. The HCI specialists, shaped by their historical body, relied on very traditional HCI methods. Then again, they also were heavily inspired by participatory design tradition and prioritized users' participation and contribution. Interesting from the perspective of $\mathrm{HCI}$ is the emergence of pedagogical design as a competitor in design. The HCI specialists in the project were not prepared for this: it was a surprise that several parties assumed authority to design the learning application.

\section{CONCLUDING DISCUSSION}

There is increasing interest in understanding and conceptualizing our research practice, particularly such that entails design, in HCI. However, reflective discussion and in-depth inquiries on our research practice and on associated practicalities and challenge, are yet limited. Moreover, so far there is limited discussion around the cross-disciplinary nature of our research and design practice: even if cross-disciplinarity is seen as an ideal and a necessity both in HCI and Design Research communities, there are limited studies on the practicalities and challenges involved in Design Research projects. If challenges or conflicts are reported, those concern different user groups or communities involved or collaboration with other disciplines than design. The literature seems to position the Design Researcher rather as a conflict resolver and sympathetic facilitator than as active agent in the struggles with her vested interests, agendas and disciplinary baggage.

To offer empirical insights into our research practice entailing design and cross-disciplinary collaboration, this study examined a cross-disciplinary research project with nexus analytic lens. Nexus analysis emphasizes that we as designers and researchers as well as our bodies, work practices and tools used, are all shaped by discourses circulating around, by different histories and backgrounds, and by other people involved. We and our design and research outcomes are both shaped by this. In the examined cross-disciplinary research project a number of researcher-designers representing different disciplines and acting as 'designers', were identified, each having a divergent understanding of design and who has authority to do it. Various kinds of discourses, epistemologies and histories were shown as shaping their research and design work.

The educational science specialists grasped a very influential position in the project; they initially created, inspired by their earlier experience as well as by theoretical insights and justifications, the design of the tutor feature that the IT specialists later implemented. Later on, the HCI specialists entered the scene with their 
baggage of HCI methods and tools as well as their users. Both theory driven pedagogical design discourse and user centered, participatory design discourse were identified as influential in this social action - shaping the designers and speaking through them. The discourse of the educational science specialists was prominent in the beginning, while the HCI specialists with their gained more eminence later on. Interestingly, the IT specialists were mainly obediently implementing the design.

As for historical body and interaction order, the technology and method repertoires of these diverse designers became accentuated. Three different disciplinary systems were involved in structuring the design process. Educational science theory based justifications legitimized the design of the educational science specialists, while users' presence and voice allowed authority for the HCI specialists. Shared background in software engineering gave authority for the work of HCI specialists and IT specialists: the deliverables and the development model were derived from that discipline, while the lack of software engineering background caused challenges for the educational science specialists. Then again, software engineering definitely did not dominate this design discourse but it was the "soft-side" that was having a say and power struggle in this design discourse. While the method and tool repertoires of software engineering and HCI strongly structured this design process, educational science with the notion of pedagogical design emerged as a potential design discipline, too - the educational science specialists even claiming authority to settle the design solution, leaving to the disciplines of HCI and software engineering only evaluator and implementer positions.

\subsection{Variety of Ontological and Epistemological Assumptions in Design Research}

For researchers interested in contemplating on the nature of our research and design practices, this study makes visible the variety of ontological and epistemological assumptions that may be involved. Interestingly, in this case, the educational science specialists came close to design science [23, 25], discussed extensively in the IS literature [24]. They saw design as heavily theory driven and motivated their design choices through reference to famous educational science scholars. The HCI specialists, then again, relied heavily on the participatory view of design (e.g. [6, 27, 29], which prioritizes users' participation and influence. Regarding the epistemologies involved, the educational science specialists adhered to a theory driven, i.e. an elite a priori type of discourse (cf. [59]), within which a priori defined theories drive the design, and they may even be tested through design, whereas the HCI specialists followed a data driven, i.e. local, emergent type of discourse (cf. [59]), within which user data is allowed to tell a story and findings are to emerge through in-depth engagement with the data, emergence and local meanings making. One may point out that the creative view of design [27] that is most closely connected with the Design Research tradition, particularly Research through design, emphasizing invention, imagination, expertise, judgement, meanings making, reflection, and improvisation of professional designers, was less strong in this case. The HCI specialists were heavily advocating user driven design process and outcome and less prioritizing their own designer identity, creativity and professionalism.

Overall, the paper wishes to make visible the potentiality of multitude of design methods, design disciplines and researcher-designer identities involved in our research and design projects. Pierce and colleagues, discussing critical design, argue that: "We need to recognize and articulate differences among practices within HCI that combine "criticality" and "design" without force fitting them into a 'critical design' straitjacket." [60: 2087] Inspired by that, this paper tries to articulate differences among practices within or in relation to HCI that combine research and design as well as argues for not trying to force fit these practices into any straitjacket.

\subsection{Critical Reflection on Our Research Practice}

This paper wishes to open a space for critical reflection around our research practice that entails design. Even if reflective discussion on our research practice is ongoing (e.g. [1, 2, 3, 4, 5, 19]), we should conduct more in-depth and critical studies on our practice. HCI community should start more openly addressing the complexities involved. We should not shy away from acknowledging how our bodies, our work practices and our tools used are shaped by discourses circulating around, by different histories and by powerful disciplinary systems, and by other people involved. Even if in Design Research there seems to be hostility towards disciplining Design Research (see e.g. [19, 26, 28]), we should acknowledge that our disciplinary backgrounds - among other factors - are strongly making and shaping us as designers.

Moreover, when discussing the conflict laden research and design processes, we should not be characterized only as sympathetic conflict resolvers or facilitators of collaboration, but we should acknowledge and show that we are active agents in the struggles with vested interests, 
agendas and a lot of baggage. Acknowledgement of the complexities involved should help developing our practice - especially if more emancipatory, empowering, sensitive, and inclusive practice is to be aimed at (e.g. [28, 29, 30, 31, 32]), our own positioning, baggage and practice should definitely be placed under critical scrutiny, too.

In this cross-disciplinary case, none of the researcherdesigners were prepared for the emergence of multiple researcher-designer groups relying on different epistemologies and researcher subjectivities, and conflicts ensued. Conflicts as such as not necessarily harmful or something that should be eliminated in research and design. Quite the opposite: they are to be seen as a natural part of human life and intimately intertwined with our research and design practices (see e.g. [43, 44]). In critical or adversarial design, disagreement and confrontation, contestation and dissensus are even to be intentionally aroused by the means of design [30, 31, 32]. However, in the research project examined in this paper, the participants were not prepared for the conflicts arousing among the researcher-designer team. Overall, in the literature so far, there seems to be less focus on disagreement and confrontation, contestation and dissensus within researcher-designer teams - rather it is expected to be found among the user or community participants or in relation other disciplines than design. We need to carefully rethink our ontological and epistemological assumptions about research and researcher-designers practicing it - those assumptions heavily shape what kind of knowledge we produce and can even imagine at producing. Along these lines, we need to scrutinize as well as celebrate the conflictual, agonistic nature of our own collaborative research and design practices.

\subsection{Value of Nexus Analysis as Theoretical Lens}

This study also contributes by introducing a novel theoretical lens inspired by nexus analysis [20,21] for making sense of our research and design practices. The lens makes visible that those should be examined as social action that entails both concrete actions and discourses circulating around as well as historical bodies of the participants and interaction orders among them. Moreover, trajectories are to be followed: how all this evolves in real time and place. Hence, nexus analysis allows studying (cross-disciplinary) research and design in quite a complexity - including both situational aspects and broader (societal, cultural, political) concerns as well as material, historical and social facets. Nexus analysis offers a systematic approach for addressing them and a common terminology for doing it (cf. [52]).

Research contemplating on our research and design practices, including cross-disciplinary ones, should acknowledge that histories, interaction orders and discourses at various levels are involved - helping or hindering our work. Researchers should utilize these concepts for making sense of their data as well as for planning their projects. They should try to anticipate what kind of baggage people bring in into research and design projects (e.g. their social and cultural capital - their networks and contacts, their knowledge and skills, influential disciplinary and professional bodies of knowledge), what kind of societal or situational discourses may be involved (e.g. societal concerns, situational discourses created by the participants arguing for authority), how the participants may be collaboratively shaping their mutual (power) relationships (taking into account e.g. their existing relationships and histories, personalities, status and hierarchy, conventions, division of work), how some particular methods will be structuring the research and design processes and shaping the researcher-designers (as part of their historical body) and how such methods are negotiated in action by the participants. During the projects, the same dynamics may be observed as evolving in real time and place, forming complex trajectories of people, objects, events and knowledge [50]. After the projects, the same conceptual tools can be used for making sense of and evaluating the trajectories emerged.

\subsection{Design Implications}

This study maintains that designers should take advantage of the nexus analytic concepts in their design practice. They should acknowledge that when they design, there definitely are relevant discourses circulating around and that historical bodies of people and their interaction orders created in situ or inscribed in conventions, rules and norms need to be understood but also their evolution and change appreciated. These do not form fixed entities to be revealed from the world, but instead they form complex, continuously changing constellations, consideration and appreciation of which nevertheless should be valuable for self-reflection purposes as part of professional practice.

Designers should also consider better support for crossdisciplinary research and design, targeting the facets of discourses in place, interaction order and historical body in particular. Support for researcher/designer's self- 
reflection [61] and articulation work [62] regarding various, potentially divergent epistemologies, discourses, traditions, method repertoires, technology experiences, and preferences is needed for cross-disciplinary teams to create a shared design space. The support should enable a team to mutually articulate and negotiate already during the early phases of a project what kind of disciplines or bodies of knowledge are involved in the project, their basic assumptions about research, design, design authority etc., their method repertoires as well as the relevant societal discourses circulating around. The same would be valuable also as regards each individual: self-reflection around individual experiences, assumptions and preferences should be aroused. Then again, as these assumptions and experiences will evolve and mutually shape each other as the project progresses, support for regular group reflection and negotiation would also be valuable.

\subsection{Limitations and Future Work}

Future work is needed to scrutinize the complexities involved with cross-disciplinary research and design involving several design disciplines - each making particular kinds of designers. The results are based on one project with many peculiarities. HCI researchers should start reflecting on our research and design practice and associated challenges more broadly to gain a more comprehensive and nuanced picture. More studies utilizing and experimenting with the nexus analytic framework are also warmly welcomed to make sense of research and design as social action.

\section{REFERENCES}

[1] W. Gaver. 2012. What should we expect from research through design? In Proc. SIGCHI conference on human factors in computing systems, 937-946. ACM.

[2] J. Zimmerman, J. Forlizzi and S. Evenson. 2007. Research through design as a method for interaction design research in HCI. In Proc. SIGCHI conference on Human factors in computing systems, 493-502. ACM.

[3] J. Zimmerman, E. Stolterman and J. Forlizzi. 2010. An analysis and critique of Research through Design: towards a formalization of a research approach. In Proc. 8th ACM Conference on Designing Interactive Systems, 310-319. ACM.

[4] J. Beck and E. Stolterman. 2016. Examining Practical, Everyday Theory Use in Design Research. She Ji: The Journal of Design, Economics, and Innovation, 2(2), 125-140.

[5] J. Beck and E. Stolterman. 2016. Examining the types of knowledge claims made in design research. She Ji: The Journal of Design, Economics, and Innovation, 2(3), 199-214

[6] I. Koskinen, J. Zimmerman, T. Binder, J. Redstrom and S. Wensveen. 2011. Design research through practice: From the lab, field, and showroom. Elsevier.

[7] J. Bardzell, S. Bardzell and L. Koefoed Hansen. 2015. Immodest proposals: Research through design and knowledge. In Proc. 33rd Annual ACM Conference on Human Factors in Computing Systems, 2093-2102. ACM.

[8] C. Frayling. 1993. Research in Art and Design. Royal College of Art Research Papers 1, 1,1-5.

[9] P. Stappers and E. Giaccardi. 2017. Research through Design. In The Encyclopedia of Human-Computer Interaction. Idea Group Reference, 1-94.
[10] P. D. Adamczyk and M. B. Twidale. 2007. Supporting multidisciplinary collaboration: requirements from novel HCI education. In Proc. SIGCHI Conference on Human Factors in Computing Systems, 1073-1076. ACM.

[11] E. Blevis and E. Stolterman. 2009. FEATURE Transcending disciplinary boundaries in interaction design. interactions, 16(5), 48-51.

[12] E. Blevis, I. K. Koskinen, K. Lee, S. Bødker, L. Chen, Y. Lim, H. Wei and R. Wakkary. 2015. Transdisciplinary Interaction Design in Design Education. In Proc. 33rd Annual ACM Conference Extended Abstracts on Human Factors in Computing Systems, 833-838. ACM.

[13] P. Jennings, E. Giaccardi and M. Wesolkowska. 2006. About face interface creative engagement in the new media arts and HCI. In CHI '06 Extended Abstracts on Human Factors in Computing Systems, 1663-1666. ACM.

[14] R. Khaled and G. Ingram. 2012. Tales from the front lines of a large-scale serious game project. In Proc. SIGCHI Conference on Human Factors in Computing Systems, 69-78. ACM.

[15] G. Moore and D: Lottridge. 2010. Interaction design in the university: designing disciplinary interactions. In CHI '10 Extended Abstracts on Human Factors in Computing Systems 2735-2744. ACM.

[16] C. Morrison, R. Corish and A. J. Sellen. 2014. Place-onas: shared resource for designing body tracking applications. In CHI '14 Extended Abstracts on Human Factors in Computing Systems, 1861-1866 ACM,

[17] Y. Rogers, M. Scaife and A. Rizzo. 2005. Interdisciplinarity: An emergent or engineered process. Interdisciplinary collaboration: An emerging cognitive science, 265-285.

[18] K. van Turnhout, A. Bennis, S. Craenmehr, R. Holwerda, M. Jacobs, R. Niels, L. Zaad, S. Hoppenbrouwers, D. Lenior and R. Bakker. 2014. Design patterns for mixed-method research in HCI. In Proc. 8th Nordic Conference on Human-Computer Interaction, 361-370. ACM.

[19] M. Held. 2016. Transdisciplinary Research through Design - Shifting Paradigms as an Opportunity. In Design as Research: Positions, Arguments, Perspectives. Birkhäuser. 186-192.

[20] R. Scollon. 2001. Action and text: towards an integrated understanding of the place of text in social (inter) action, mediated discourse analysis and the problem of social action. In Methods of critical discourse analysis, 113.

[21] R. Scollon and S. Scollon. 2004. Nexus analysis: Discourse and the emerging internet. Routledge.

[22] S. Scollon and I. de Saint-Georges. 2012. Mediated discourse analysis. In The Routledge Handbook of Discourse Analysis. Routledge. 66-78.

[23] N. Cross. 2001. Designerly ways of knowing: Design discipline versus design science. Design issues, 17(3), 49-55.

[24] A. Hevner. 2007. A three cycle view of design science research. Scandinavian journal of information systems, 19(2), 4.

[25] S. March and G. Smith. 1995. Design and natural science research on information technology. Decision support systems, 15(4), 251-266.

[26] W. Gaver. 2016. Indiscipline. In Design as Research: Positions, Arguments, Perspectives. Birkhäuser. 193-196.

[27] J. Löwgren. 1995. Applying design methodology to software development. In Proc. 1st conference on Designing interactive systems: processes, practices, methods, \& techniques, 87-95. ACM.

[28] K. Krippendorff. 2016. Design, an Undisciplinable Profession. In Design as Research: Positions, Arguments, Perspectives. Birkhäuser. 197-206.

[29] J. Simonsen and T. Robertson (Eds.). 2012. Routledge international handbook of participatory design. Routledge.

[30] N. Iivari and K. Kuutti. 2017. Critical Design Research and Information Technology: Searching for Empowering Design. In Proc. 2017 Conference on Designing Interactive Systems, 983-993. ACM.

[31] C: DiSalvo. 2012. Adversarial design. The MIT Press.

[32] S. Bardzell, J. Bardzell, J. Forlizzi, J. Zimmerman and J. Antanitis. 2012 Critical design and critical theory: the challenge of designing for provocation. In Proc. Designing Interactive Systems Conference, 288-297. ACM.

[33] B. Choi and A. Pak. 2006. Multidisciplinarity, interdisciplinarity and transdisciplinarity in health research, services, education and policy: 1 Definitions, objectives, and evidence of effectiveness. Clinical and investigative medicine. Medecine clinique et experimentale, 29(6), 351-364.

[34] J. Greenbaum and M. Kyng (Eds.). 1991. Design at Work. Cooperative Design of Computer Systems, Lawrence Erlbaum Associates.

[35] F. Kensing and J. Blomberg. 1998. Participatory Design: Issues and Concerns. Computer Supported Cooperative Work 7(3-4), 167-185.

[36] C. Cooper and J. Bowers. 1995. Representing the users: Notes on the disciplinary rhetoric of human-computer interaction. In The Social and Interactional Dimensions of Human-Computer Interfaces. Cambridge University Press. 48-66.

[37] J. Gulliksen, I. Boivie and B. Göransson. 2006. Usability professionalscurrent practices and future development. Interacting with computers, 18(4), 568-600.

[38] N. Iivari. 2006. Understanding the work of an HCI practitioner. In Proc. 4th Nordic conference on Human-computer interaction. 185-194. ACM. 
[39] N. Iivari, H. Karasti, T. Molin-Juustila, S. Salmela, A. Syrjänen and E. Halkola. 2009. Mediation between design and use - revisiting five empirical studies. Human IT - Journal for Information Technology Studies as a Human Science 10(2), 81-126.

[40] K. Lawrence. 2006. Walking the Tightrope: The Balancing Acts of a Large eResearch Project. Computer Supported Cooperative Work 15(4), 385-411.

[41] C. Lee. 2007. Boundary Negotiating Artifacts: Unbinding the Routine of Boundary Objects and Embracing Chaos in Collaborative Work. Computer Supported Cooperative Work 16(3), 307-339.

[42] N. Levina and E. Vaast. 2005. The Emergence of Boundary Spanning Competence in Practice: Implications for Implementation and Use of Information Systems. MIS Quarterly 29(2), 335-363.

[43] E. Björgvinsson, P. Ehn and P. Hillgren. 2012. Agonistic participatory design: working with marginalised social movements. CoDesign, 8(2-3), 127-144.

[44] E. Grönvall, L. Malmborg and J. Messeter. 2016. Negotiation of values as driver in community-based PD. In Proc. 14th Participatory Design Conference: Full papers-Volume 1, 41-50. ACM.

[45] C. Hooper, D. Millard, J. Fantauzzacoffin and J. Kaye. 2013. Science vs. science: the complexities of interdisciplinary research. In CHI '13 Extended Abstracts on Human Factors in Computing Systems, 2541-2544. ACM.

[46] M. Murer, M. Jacobsson, S. Skillgate and P. Sundström. 2014. Taking things apart: reaching common ground and shared material understanding. In Proc SIGCHI Conference on Human Factors in Computing Systems, 469-472. ACM.

[47] M. Rau, V. Aleven, N. Rummel and S. Rohrbach. 2013. Why interactive learning environments can have it all: resolving design conflicts between competing goals. In Proc. SIGCHI Conference on Human Factors in Computing Systems, 109-118. ACM.

[48] P. Bourdieu. 1984. Distinction: A social critique of the judgement of taste. Harvard University Press.

[49] E. Goffman. 1983. The interaction order: American Sociological Association, 1982 presidential address. American sociological review, 48(1), 1-17.
[50] T. Keisanen and L. Kuure. 2011. Practices of multidisciplinary collaborative work: Wiki document as a boundary object. Kielenkäyttö verkossa ja verkostoissa, 57-71.

[51] N. Iivari, M. Kinnula, L. Kuure and T. Molin-Juustila. 2014. Video diary as a means for data gathering with children-Encountering identities in the making. International Journal of Human-Computer Studies, 72(5), 507-521

52] T. Molin-Juustila, M. Kinnula, N. Iivari, L. Kuure and E. Halkola. 2015. Multiple voices in ICT design with children-a nexus analytical enquiry. Behaviour \& Information Technology, 34(11), 1079-1091.

[53] G. Walsham. 2006. Doing interpretive research. European Journal of Information Systems 15, 320-30.

[54] T. Schwandt. 2000. Three Epistemological Stances for Qualitative Inquiry: Interpretivism, Hermeneutics, and Social Constructionism. In Handbook of Qualitative Research. Sage. 189-214.

[55] G. Walsham. 1995. Interpretive case studies in IS research: nature and method. European Journal of Information Systems 4, 74-81.

[56] N. Denzin and Y. Lincoln. 2000. Introduction: The Discipline and Practice of Qualitative Research. In Handbook of Qualitative Research. Sage, 1-29.

[57] J. Clifford. 1986. Introduction: Partial Truths. In Writing culture: the poetics and politics of ethnography. University of California Press. 1-26.

[58] Y. Lincoln and E. Guba. 2000. Paradigmatic Controversies: Contradictions and Emerging Confluences. In Handbook of Qualitative Research. Sage. 163-188.

[59] S. Deetz. 1996. Crossroads-Describing differences in approaches to organization science: Rethinking Burrell and Morgan and their legacy. Organization science, 7(2), 191-207.

[60] J. Pierce, P. Sengers, T. Hirsch, T. Jenkins, W. Gaver and C. DiSalvo. 2015 Expanding and refining design and criticality in HCI. In Proc. 33rd Annual ACM Conference on Human Factors in Computing Systems, 2083-2092. ACM

[61] K. Yip. 2007. Self-reflection in reflective practice: a Jaspers' orientation. Reflective practice $8(2), 285-298$

[62] L. Suchman. 1996. Supporting articulation work. Computerization and controversy: Value conflicts and social choices, 2, 407-423. 